Review Article

\title{
Precise Blood Glucose Sensing by Nitrogen-Doped Graphene Quantum Dots for Tight Control of Diabetes
}

\author{
Seyyed Mojtaba Mousavi $\mathbb{D}^{1},{ }^{1}$ Seyyed Alireza Hashemi $\mathbb{D}^{2},{ }^{2}$ Ahmad Gholami $\mathbb{D}^{3},{ }^{3}$ \\ Sargol Mazraedoost $\mathbb{D}^{3},{ }^{3}$ Wei-Hung Chiang $\mathbb{D}^{1},{ }^{1}$ Omid Arjmand, ${ }^{4}$ Navid Omidifar $\mathbb{C D}^{4,5}$ \\ and Aziz Babapoor ${ }^{6}$ \\ ${ }^{1}$ Department of Chemical Engineering, National Taiwan University of Science and Technology, Taipei, Taiwan \\ ${ }^{2}$ Nanomaterials and Polymer Nanocomposites Laboratory, School of Engineering, University of British Columbia, Kelowna, BC, \\ Canada V1V 1 V7 \\ ${ }^{3}$ Pharmaceutical Sciences Research Center, Shiraz University of Medical Sciences, Shiraz, Iran \\ ${ }^{4}$ Biotechnology Research Center, Shiraz University of Medical Sciences, Shiraz, Iran \\ ${ }^{5}$ Department of Pathology, School of Medicine, Shiraz University of Medical Sciences, Shiraz, Iran \\ ${ }^{6}$ Department of Chemical Engineering University of Mohaghegh Ardabili (UMA) Ardabil, Iran
}

Correspondence should be addressed to Ahmad Gholami; gholami@sums.ac.ir and Wei-Hung Chiang; whchiang@mail.ntust.edu.tw

Received 21 February 2021; Accepted 24 June 2021; Published 17 July 2021

Academic Editor: J.G. Manjunatha

Copyright (c) 2021 Seyyed Mojtaba Mousavi et al. This is an open access article distributed under the Creative Commons Attribution License, which permits unrestricted use, distribution, and reproduction in any medium, provided the original work is properly cited.

Graphene quantum dots (GQD) are novel fluorescent carbon nanomaterials based on a graphite structure. Thanks to extraordinary properties such as high surface area and enhanced prevalent optical properties, they have received more interest for special applications. Glucose sensing is a critical factor for the diagnosis, and treatment of diabetes plays an important role and could contribute to the monitoring of diabetes and other related parameters, which has been effectively underscoring the health society. Detecting glucose has been cultivated through different systems, for example, electrochemical or optical techniques. Novel transducers made with GQD that fluorescent coordinate methods have considered the improvement of cutting-edge glucose sensors with prevalent affectability and accommodation. Currently, detection of glucose by nitrogen-doped GQD frameworks concerning the determined objectives has been considerably considered. Here, we explored the properties of fluorescent nitrogen-doped GQD as an excellent and effective index that significantly could promote nitrogen-doped GQDs and make them an appropriate candidate for detecting glucose.

\section{Introduction}

An extraordinary investigation among building up the graphene and its subordinates has recently been animated for upgraded clinical advances. As a two-dimensional honeycomb organizer comprising sp2 hybridized carbon ( $\mathrm{sp} 2 \mathrm{C}$ ) iotas, graphene has shown many superior synthetic and physical properties because of this specific two-dimensional layered structure [1]. Diabetes is a metabolic disease, revealed by blood glucose maintenances and reasons with long haul harm and breakdown of different organs, just like the eyes, kidney, heart, and veins [2]. The initial and delicate disclosure of unpredictable glucose levels interior the blood is exceptionally fundamental for veritable treatment to decrease different thriving issues $[2,3]$. Diabetes mellitus is a ceaseless condition that influences more than 420 million individuals worldwide and is the primary source of death [4]. Diabetic individuals have fundamental degrees of blood glucose in controlling glycemic levels and decreasing the indications of the illness. Glucose sensors have been utilized for diabetes for over 50 years, given that Clark and Ann Lyons developed the principal glucose catalyst in 1962. Electrochemical sensors have 
improved the indispensable innovation for estimating glucose levels with the most broadly accessible strategies for amperometric detection. In expansion, distinguishing glucose in the blood is a broad research component [5-8]. The improvement of new fluorescent nanomaterials opened a weak outlook so that the level of blood glucose be controlled at average level as it is expected. Such sensors incorporate nanoparticles containing carbon dabs, quantum spots, graphene quantum dabs, gold, silver, and upconversion [9]. A modest bunch of methodologies has been utilized to form the glucose biosensors subordinate to glucose oxidase protein. In any case, the immobilization of a protein on the cathode surface may be an especially testing task, and it is thoroughly influenced by temperature, $\mathrm{pH}$, and clamminess, which causes down and out unfaltering quality $[10,11]$. Along these lines, nonenzymatic glucose sensors are supported and have been widely investigated and considered [12]. Graphene as a promised material, depending on its excellent features in a wide range of scientific fields, such as photonic gadgets, low force hardware, electrochemical vitality and capacity frameworks, impetuses, organic and synthetic sensors, bioimaging, and tissue engineering, is widely utilized $[13,14]$. Graphene could easily modify various surfaces as used, making it an excellent material with a few side effects $[15,16]$. Doping nitrogen on GQDs was first introduced in 2012, and from that point onward, more endeavors have been made for investigating various techniques for DFCDs with different heteroatoms [17-19]. Yet, before treating individuals with diabetes, the precise, quick, and stable discovery of glucose level is the most extreme genuine errand for the individuals who will probably get individuals with diabetes [20]. Hence, nonenzymatic glucose biosensors have been grown as of late to the clinical network. Subsequently, these nonenzymatic glucose biosensors have revealed much prevalent adequacy and affectability that other enzymatic sensors and have been made a bundle during the previous decades, and entering GQDs to this sensor have caused a colossal adjust in glucose revelation [16, 21-24].

\section{GQDs and Nitrogen-Doped GQD Preparation}

The GQDs are mainly composed of glucose pyrolysis, as illustrated in (Figure 1). Generally, GQDs are prepared in two ways called the bottom-up way and the top-down way. Although, the top-down method comes with several disadvantages, including more challenging size distribution control, lower yield, critical synthesis environment, and special equipment requirements. On the other side, the bottom-up strategy, also called thermal treatment and carbonizing some unique, organic materials, generally allows specific size and morphology control over the distribution of products. However, the used organic precursors need complicated synthesis procedures and are difficult to obtain [25-28].

Recently, Liu et al. [29] reported GQDs prepared from hexaperihexabenzocoronene pyrolysis. Furthermore, GQDs were designed as starting materials from citric acid and glutathione, too $[29,30]$. In another study, Wu et al. used a simple one-step synthesis of GQSs by pyrolysis of L-glutamic acid in a heating mantle [31]. Wang and Zhou [32] also reported the Gram-scale synthesis of functionalized GQDs using pyrene through a facile molecular fusion route. Also, fluorescent nitrogen-doped graphene quantum dots were developed using the bottom-up method via one-step pyrolysis of citric acid and tris (hydroxymethyl) aminomethane $[33,34]$.

Numerous groups have attempted to make GQD by emerging carbon materials and oxidizing them with acidic compounds in the top-down route technique. Also, solvothermal and hydrothermal treatments were used for GQDs synthesis $[35,36]$. The electrochemical route might provide some benefits as essential parameters, including easy manipulation, lower cost, and more ecological. Recently, graphene film formed by filtration as cyclic voltammetry (CV) scan electrode in a phosphate buffer solution to build uniform diameter GQD at 3-5 $\mathrm{nm}$ by Li et al. [37]. Bao et al. [38] also used electrochemical etching carbon fibers for GQD preparations at a stable probable for further hours in acetonitrile explanation [38]. In another report by Shinde et al., multiwall carbon nanotubes were electrochemically transformed on a one two-step process for preparing GQD. Despite this, this electrochemical method involves a graphene-like electrode, and hence, it is not proper for the production of GQD on a large scale. Therefore, to develop an extensive scale method for GQDs preparation from GO, a group of researchers introduced an economical and novel route of electrochemical modifications. Given that the reported GQD yield was above $65.5 \%$. Hence, this method as a controllable and straightforward way for different scales of industrial levels could provide excellent performance. These GQDs provided different emission colors and sizes with noticeable peroxidase-like activity, suggesting their high potential in biosensors applications [24, 33]. Figure 2 illustrates a schematic of other methods of GQD preparation.

During the past years, doping carbon materials with nitrogen have received more attention than reported [40]. Currently, nitrogen-doped fluorescent carbon nanomaterials are widely utilized as the promoted materials in many fields, mainly in biomedical areas such as biosensing and bioimaging specific compounds, photocatalysis, electrocatalysis, and photovoltaics $[41,42]$. Here, we describe some of the biomedical applications of nitrogen-doped GQDs.

\section{Biosensing and Bioimaging Activities of Nitrogen-Doped GQDs}

Bioimaging and biosensing as two essential applications of nitrogen-doped fluorescent carbon dots to quantum dots have been put forward and considered. Many factors are required for nitrogen-doped fluorescent carbon dots or quantum dots so that they could be used as biosensors or bioimaging agents, such as a suitable PL intensity and an under approximately seven $\mathrm{pH}$ value. Additionally, their low toxicity as a key and effective parameter could contribute to achieving the best clinical efficiency as it is involved different cell types at particular concentrations with subject to the determined and targeted environment. It was worth mentioning to note that the nitrogen-doped quantum dots showed no apparent toxicity on $1 \mathrm{mg} / \mathrm{mL}$ concentration as 
<smiles>O=C[C@H](O)[C@@H](O)[C@@H](O)[C@@H](O)CO</smiles>

Glucose molecules

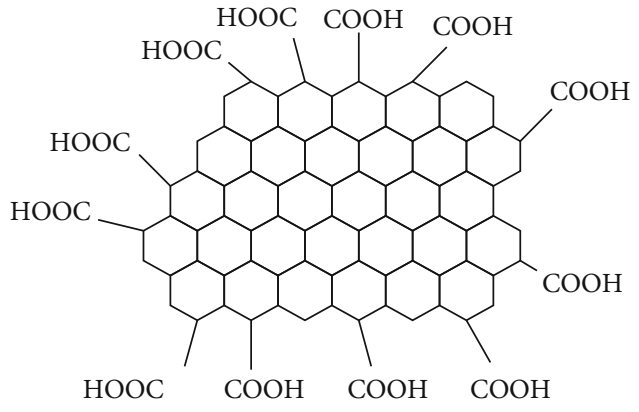

Functionalized GQDs

FIGURE 1: Schematic representation of GQD arrangement from glucose pyrolysis [29].

Top-down

Carbon resource
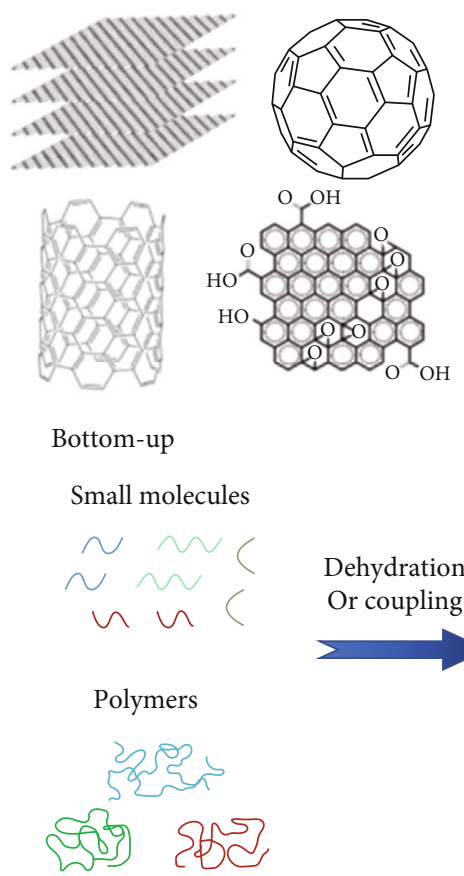
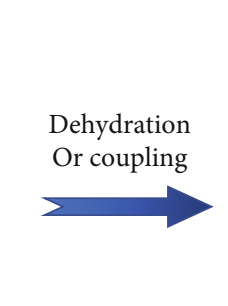

GQDs
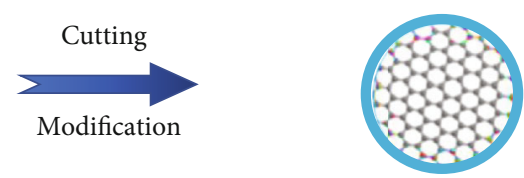

Further

carbonization

or coupling

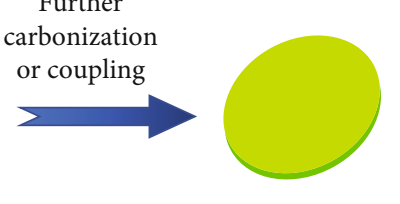

GQDs

Figure 2: Two fundamental approaches embraced to plan fluorescent GQDs: the "top-down" part course from diverse carbon sources and the "bottom-up" strategy from tiny atoms or polymers [9, 39].

prepared (Figure 3). As an additional sample, the nitrogenGQDs are formulated through pyrolysis of ethylene diamine tetraacetic acid (EDTA), indicating lower cytotoxicity, allowing the cells to maintain their feasibility even below 140 $\mu \mathrm{g} / \mathrm{mL}$ attentiveness $[32,43,44]$. The results also revealed that nitrogen-quantum dots constructed from milk presented curiously lower toxicity than one made from EDTA [45] (Figure 4(a), solid lines).

E-GQD UV-vis absorption spectrum showed the preoccupation band at about $340 \mathrm{~nm}$ (Figure 4(a), dash lines). The RAW 264.7 cells are discovered due to the strong fluorescence signal of E-GQDs (Figures 4(b)-4(d)). Additional studies confirmed that the doping quantum and carbon dots with nitrogen would grant more robust fluorescence release than the nondoped ones intended for bioimaging fields [45]. Nitrogen codoping with $\mathrm{N}$ and additional components have been utilized in cell imaging as they showed a few unpredictable behaviors in their optical possessions [42, 46].

It is concluded that the nitrogen-doped GQDs indicated a $\mathrm{pH}, \mathrm{H}_{2} \mathrm{O}_{2}$ concentration, and temperature-dependent catalytic activity with peroxiding behavior, which is similar to the HRP. In kinetic analysis, it was also revealed that nitrogen-doped GQDs showed noticeable catalytic activity. Nitrogen-doped GQDs are unique and natural enzyme mimetic, with various benefits over the natural bulk enzymes, including delicate stability, economical and low cost, higher surface area ratio, and high potential to bond through p-p interactions. Finally, using nitrogen-doped GQDs with catalytic activities and peroxidase-like behavior 


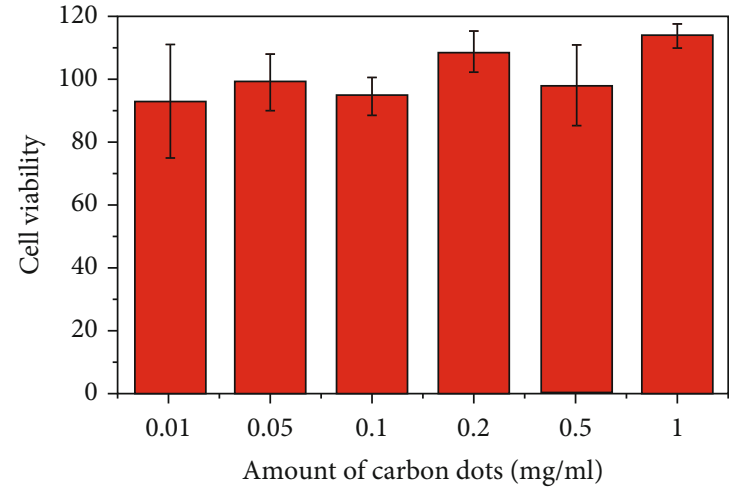

(a)

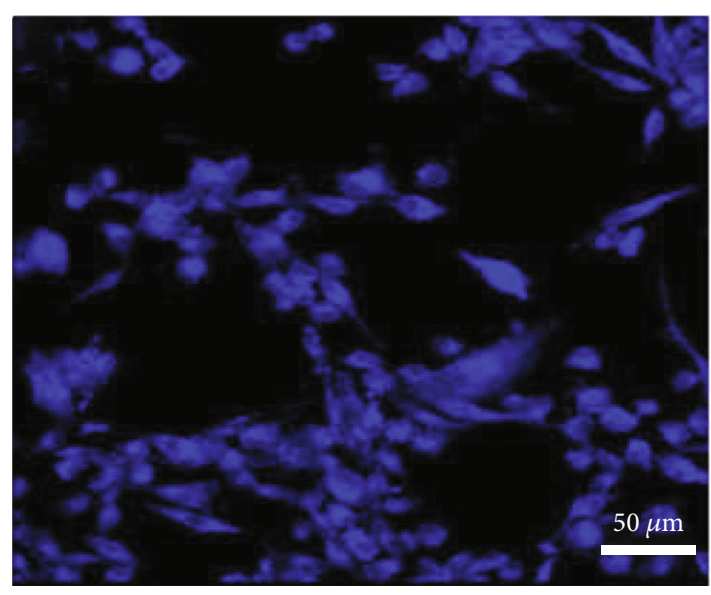

(b)

FIgure 3: (a) Cytotoxicity testing originates about utilizing a CCK-8 test. The values are given within the cell practicality rate. (b) Laser checking confocal microscopy picture of U87 cells after the cellular take-up of N-CQDs [32, 42].
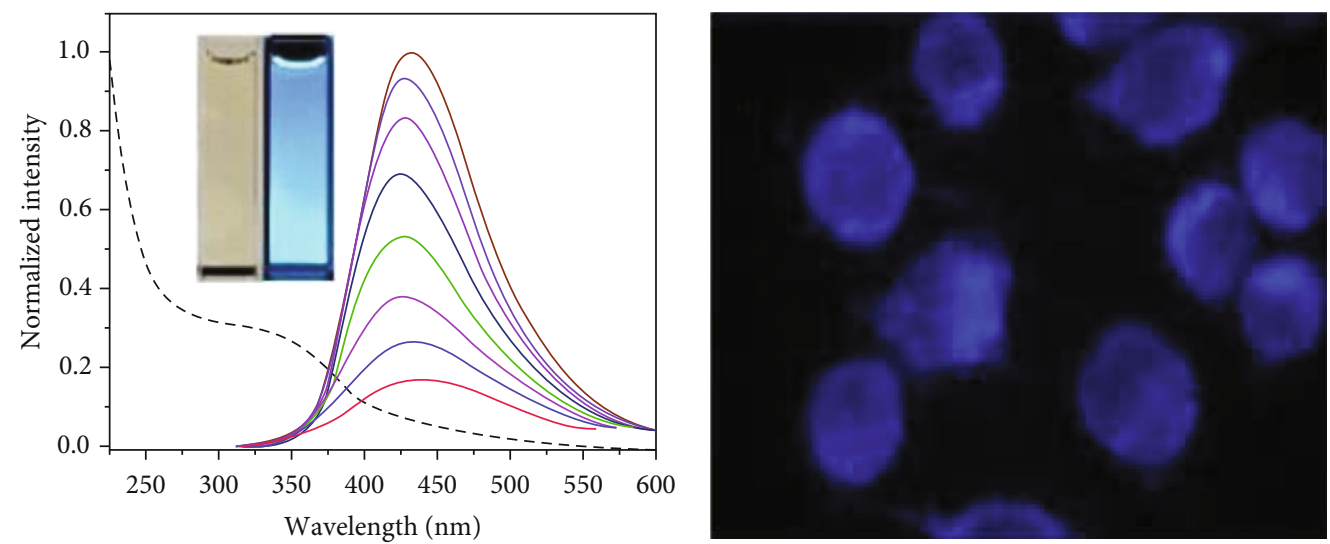

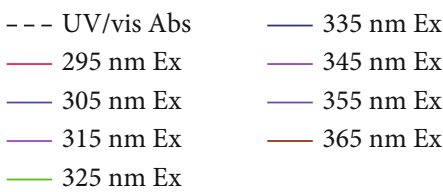

(a)

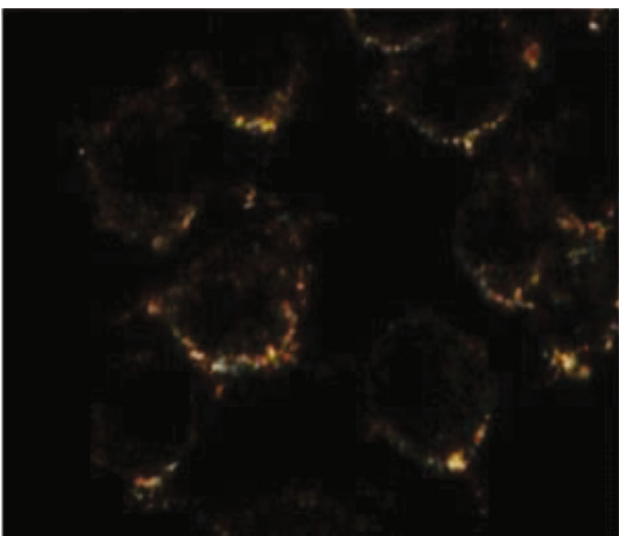

(c) (b)

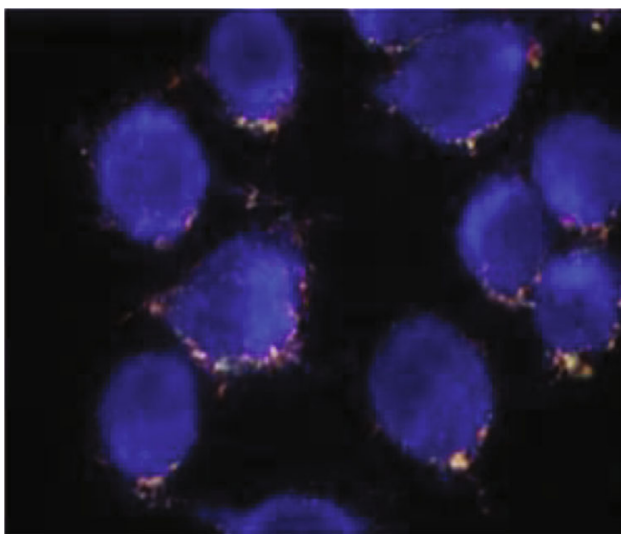

(d)

FIGURE 4: (a) Normalized UV-Vis's absorption (sprint) and PL (solid) spectra of E-GQDs. Inset: the photographs of E-GQDs within the watery course of action underneath unmistakable (cleared out) and UV (right) lights. (b) Fluorescent picture of unrefined 264.7 cells brought forth with $80 \mu \mathrm{g} / \mathrm{mLN}$-GQDs. (c) The dark-field microscopic image comparing to (b). (d) Overlay of (b) and (c) [42, 44]. 


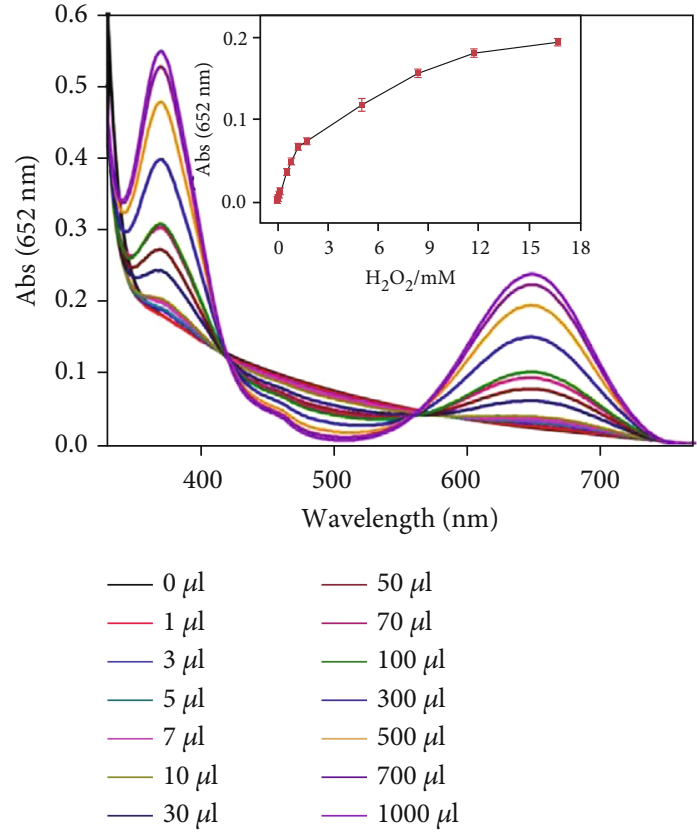

(a)

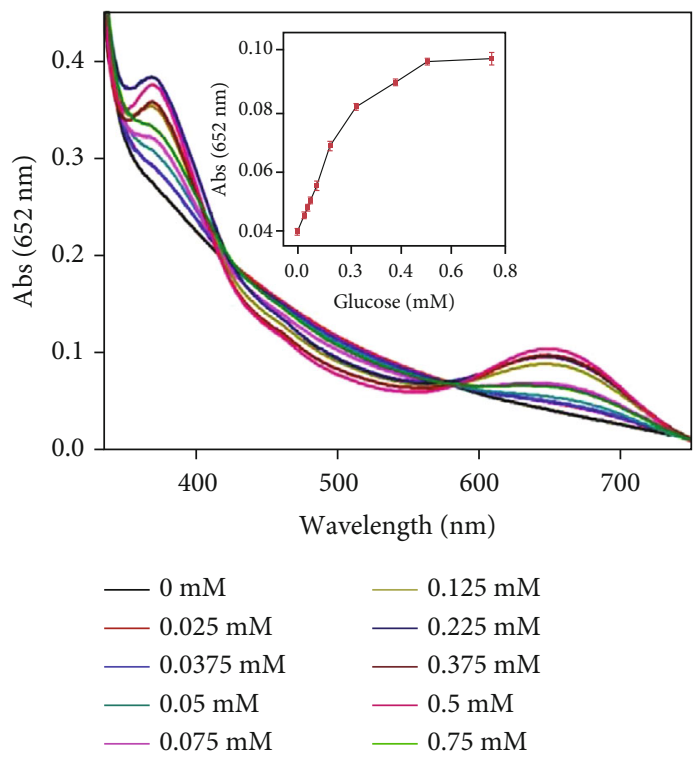

(c)

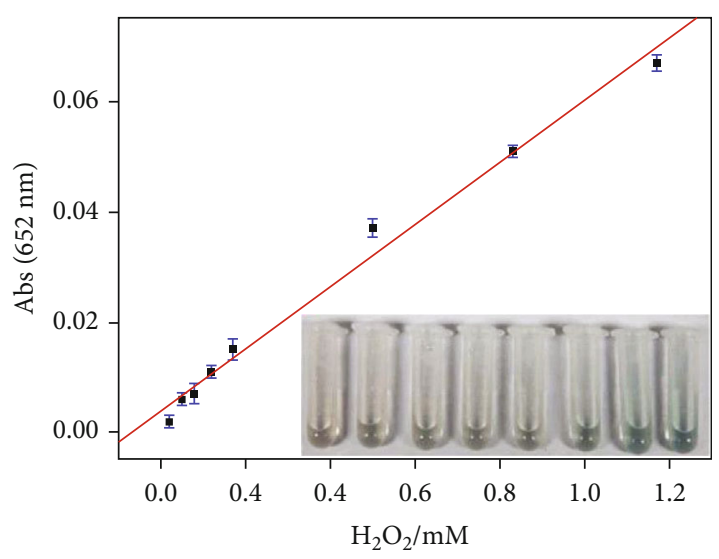

(b)

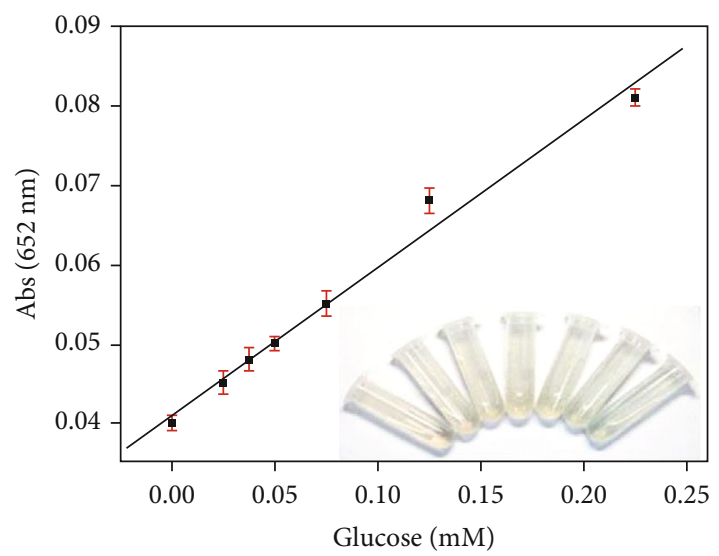

(d)

FIGURE 5: (a) UV-vis absorption spectra and (b) direct calibration plots for the $\mathrm{H}_{2} \mathrm{O}_{2}$ area utilizing N-GQD peroxidase-like catalytic reaction. (c) UV-vis digestion spectra and (d) coordinate calibration plots for the glucose area utilizing glucose oxidase (GOx) and N-GQDs (inset: dose-response twists for $\mathrm{H}_{2} \mathrm{O}_{2}$ revelation utilizing N-GQD peroxidase-like catalytic reaction (a) and glucose disclosure utilizing GOx and N-GQDs (c); photographs for colorimetric revelation for $\mathrm{H}_{2} \mathrm{O}_{2}$ (b) and glucose (d), independently). Test conditions for $\mathrm{H}_{2} \mathrm{O}_{2}$ and glucose area: $500 \mathrm{~mL} \mathrm{~N}$-GQDs $320 \mathrm{mg} / \mathrm{mL}, 200 \mathrm{~mL}$ TMB $5 \mathrm{mM}, 5 \mathrm{~mL}$ GOx $40 \mathrm{mg} / \mathrm{mL}$, and different volumes of $\mathrm{H}_{2} \mathrm{O}_{2} 50 \mathrm{mM}$ or glucose $1 \mathrm{mM}$ in $200 \mathrm{~mL} \mathrm{H} \mathrm{PO}_{4}-\mathrm{Na}_{2} \mathrm{HPO}_{4} 100 \mathrm{mM}$ buffer course of action ( $\mathrm{pH} 3.0$ ) at $35^{\circ} \mathrm{C}$. Each point is an ordinary of three dynamic estimations. Bumble bars talk to the commonplace botch decided from three dynamic estimations [47].

is a convenient and sensitive quantitative and colorimetric agent for $\mathrm{H}_{2} \mathrm{O}_{2}$ and glucose detection. Therefore, this assay was employed in diluted serum and fruit juice for glucose detection. The experimental tests (Figure 5) demonstrated nitrogen-doped GQDs as great nominees for medical diagnostics and other biomedical applications [47].

\section{The Selectivity of the Organized GQD-PBS Glucose Sensor}

Glucose revelation and identification have a significant portion in food businesses and pharmaceutical zones, and more vitally, glucose identifying is outstandingly fundamental for 


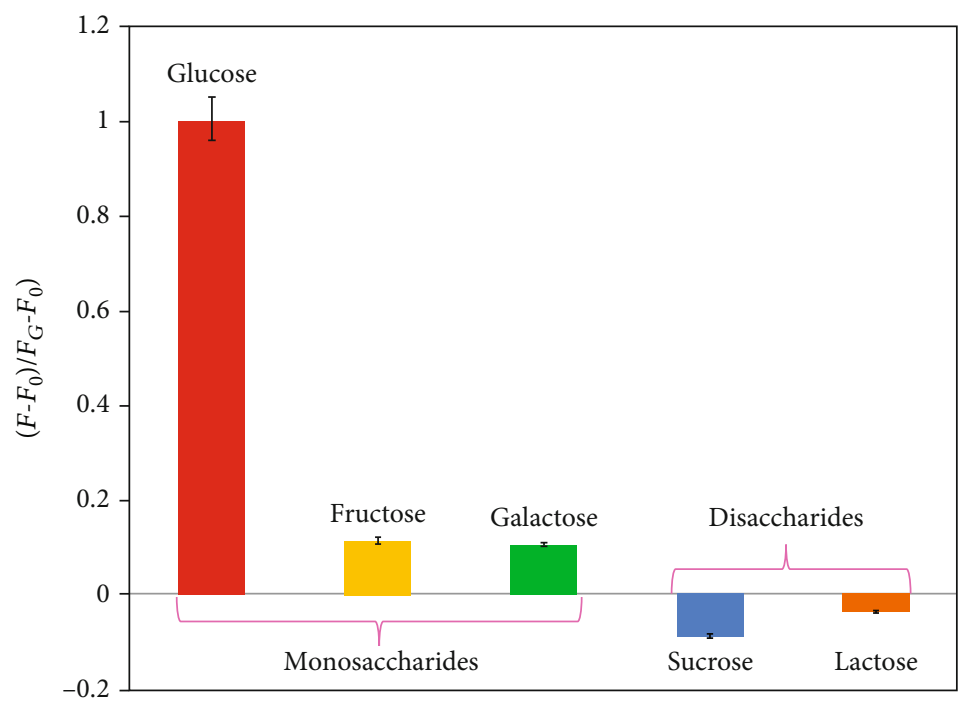

Figure 6: The general centralization of the fluorescence $\left(F-F_{0}\right) /\left(F_{G}-F_{0}\right)$ of specific saccharides. $F$ and $F_{0}$ speak to the fluorescence raised interior, the nonattendance, and vicinity of $40 \mathrm{mM}$ saccharides. $F_{G}$ appears up the fluorescence concentrated with $40 \mathrm{mM}$ glucose [33].

curing diabetes. Diabetes is considered as long-term hyperglycemia, and so the glucose area is essential for controlling the illness. The detection of glucose using the electrochemical approach may be put forward as a standard procedure for recognizing blood glucose resistance to insulin. In any case, the blood test-taking preparation may be considered a poorly designed way for testing; conjointly, the risk of infection could be a stressful issue for numerous individuals. In this manner, characteristic working frameworks, being noninvasive or minor obtrusive fluorescent location innovations, have innumerable interfaces [48]. Fluorescent detecting provides different benefits. In quintessence, being exceedingly touchy more than other detecting strategies, noninvasive or minor obtrusive, the life expectancy of fluorescence escalated is utilizable, and the fluorescent reverberation vitality approach can be functionalized as well. The root of glucose fluorescent location is unexpected on glucose signals being changed over to a connected fluorescence flag.

For this aim, a glucose-recognized biomolecule with a flag finder and transducer is required [49]. Nanomaterials with fluorescence movement are perfect flag transducers for connecting glucose signals into fluorescence signals, particularly in top escalated and move for a fluorescent lifetime. In nanobiosensing systems, fluorescence resonation essentialness trade (Worry) is a tried and true and redress informative technique. Nanomaterials have a high performance for finding glucose in numerous interior stages of the body or target cells. Biomolecules are exceptionally profoundly boosted in their organic action by physical adsorption or conjugation on nanomaterials for higher biological applications.

Nanobiosensing of glucose by fluorescent materials depends on the taking after instrument, as the arrangement and competitive official of glucose, at that point release of fluorescent color, which impacts the fluorescent lifetime. In other measures, catalytic oxidation responses such as gluconic corrosive $(\mathrm{pH})$ or hydrogen peroxide are utilized in glucose, making the fluorescent alter. A few glucose oxidation forms contain ATP as adenosine triphosphate and ADP as adenosine diphosphate [9]. As of late, GQDs were organized utilizing glucose carbonization handle as a required course. After that, these GQDs were functionalized using phenylboronic destructive receptors as identifying administrators for nonenzymatic glucose sensors. The photoluminescence sensor was joined, comprising phenylboronic salt, and utilized GQDs for glucose particle revelation. PBS functionalized graphene quantum spot-based sensor recognized glucose interior to reach $4-40 \mathrm{mM}$, differentiating $72-720$ $\mathrm{mg} / \mathrm{dL}$. This fluorescent sensor includes a coordinate consolidate method and can be taken care of for an allencompassing time allotment for zone applications. The utilized sensor appeared a prompt response to glucose through a relationship coefficient of 0.97 and a moo disclosure controls around 3.0 mM (Figure 6) [33].

Glucose detection and sensing have a crucial role in food industries and pharmaceutical fields, and more importantly, glucose sensing is critical for curing diabetes. Diabetes is considered as long-term hyperglycemia, and therefore, glucose detection is necessary for controlling the disease. Electrochemical glucose sensing is a standard method for patience in terms of a blood glucose meter. However, the blood sample-taking process may be considered an inconvenient way for testing, and also the risk of infection is a worrying issue for many people. Therefore, easy operating systems, being noninvasive or minor invasive fluorescent detection technologies, have many interests [50].

Also, in another study, a water-soluble, selective, and sensitive fluorescent probe for glucose detection based on $\mathrm{H}_{2} \mathrm{O}_{2}$ mediated fluorescence quenching of molybdenum disulfide quantum dots $\left(\mathrm{MoS}_{2}\right.$ QDs) was investigated. The $\mathrm{MoS}_{2}$ QDs were synthesized through an easy hydrothermal method and have water solubility, high stability, bright blue fluorescence, and high quantum yields. Significantly, the fluorescence of $\mathrm{MoS}_{2}$ QDs is found to be selectively quenched by $\mathrm{H}_{2} \mathrm{O}_{2}$. Since glucose can be oxidized by glucose oxidase to 


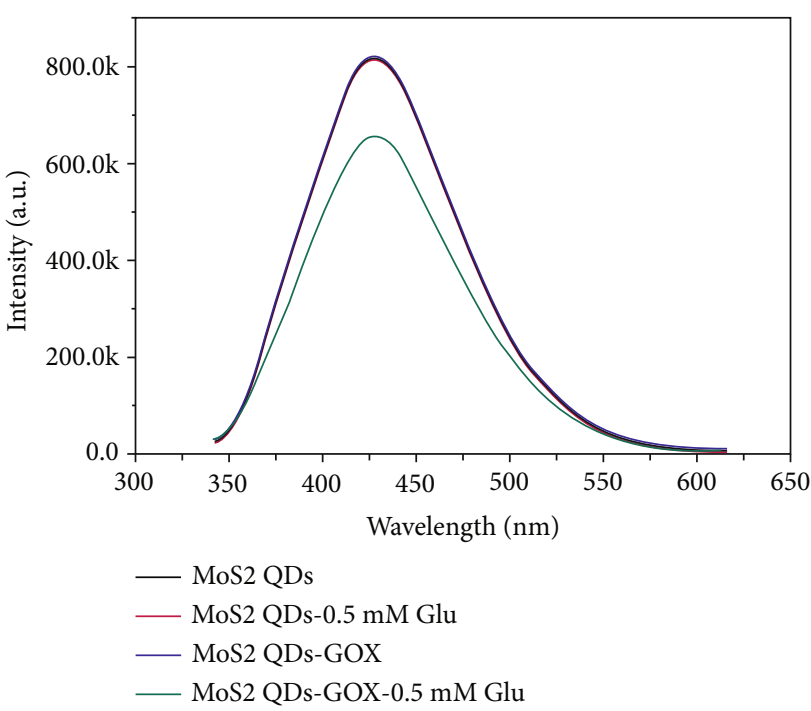

(a)

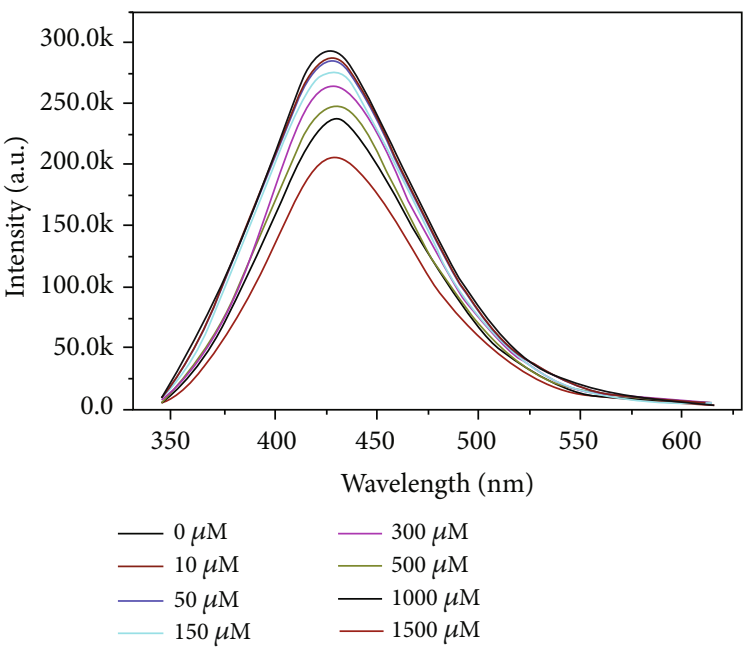

(c)

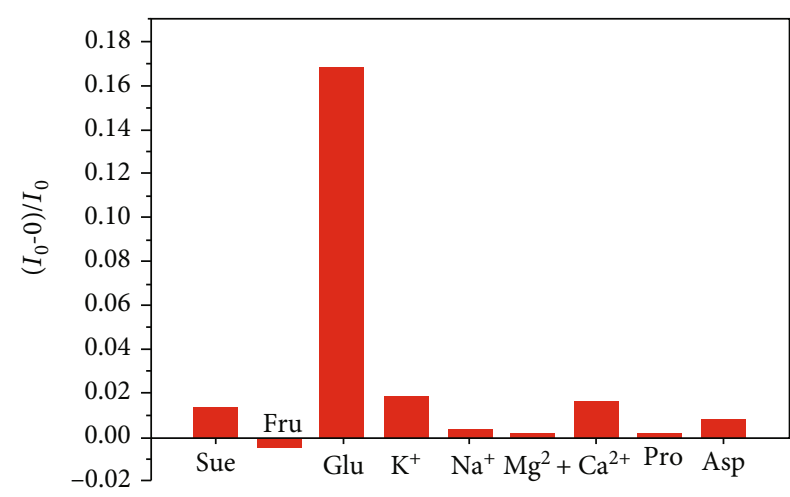

(b)

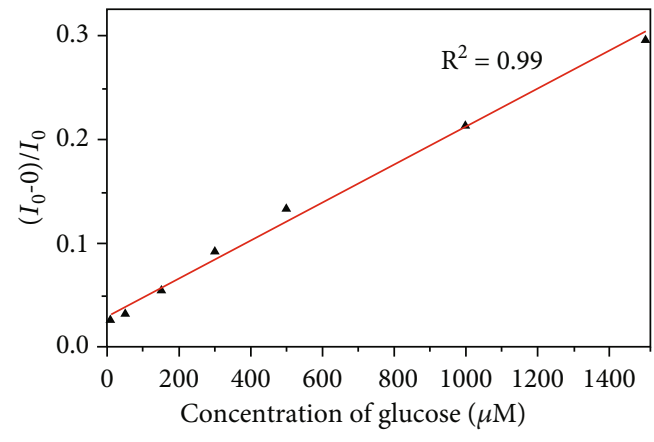

(d)

FIgure 7: (a) $\mathrm{MoS}_{2}$ QD (dull) PL spectra, $\mathrm{MoS}_{2}$ QDs between $0.5 \mathrm{mM}$ of glucose (reddish) and $0.2 \mathrm{mg} / \mathrm{mL}$ GOx (blue), $0.2 \mathrm{mg} / \mathrm{mL}$ GOx, and $0.5 \mathrm{mM}$ of glucose (green) blend. (b) Impacts of guest particles $\left(10^{-2} \mathrm{M}\right)$ and $0.5 \mathrm{mM}$ glucose on the PL-extinguishing capacity of $0.2 \mathrm{mg} / \mathrm{mL}$ GOx-containing $\mathrm{MoS}_{2}$ QDs. (c) PL spectra of $\mathrm{MoS}_{2}$ QDs containing $0.2 \mathrm{mg} / \mathrm{mL}$ GOx with an assorted sum of glucose. (d) A coordinate response of quenching capacity and glucose concentration [50].

produce $\mathrm{H}_{2} \mathrm{O}_{2}$, $\mathrm{MoS}_{2}$ QDs can be used as a convenient and selective sensor for quantitative detection of glucose. The method was also applied to detect glucose in fetal bovine serum with satisfactory results, suggesting that our approach has great potential application for diabetes mellitus research and clinical diagnosis. In addition, the results provide an alternative platform to design different novel nanosensors to detect other substrates through oxidation by oxygendependent oxidase, which could generate $\mathrm{H}_{2} \mathrm{O}_{2}$ [50].

Glucose oxidase (GOx) catalyzes the glucose oxidation to generate $\mathrm{H}_{2} \mathrm{O}_{2}$, and the detection of glucose is possible with the fluorescence quenching of $\mathrm{MoS}_{2}$ QDs by $\mathrm{H}_{2} \mathrm{O}_{2}$ as the signal transducer. To confirm the PL quenching of $\mathrm{MoS}_{2}$ QDs by $\mathrm{H}_{2} \mathrm{O}_{2}$, the PL spectra of $\mathrm{MoS}_{2}$ QDs in the presence of pure glucose, $\mathrm{GOx}$, and a mixture of glucose and GOx were investigated. It can be found that the fluorescence intensity of $\mathrm{MoS}_{2}$ QDs appeared no change in the presence of GOx or glucose, but the PL intensity decreased after the addition of glucose-containing $0.2 \mathrm{mg} \cdot \mathrm{mL}-1 \mathrm{GOx}$ (Figure $7(\mathrm{a})$ ). These results demonstrate that the PL of $\mathrm{MoS}_{2}$ QDs was quenched by $\mathrm{H}_{2} \mathrm{O}_{2}$ produced from the $\mathrm{GOx}$-catalyzed oxidation of glucose (Figure 7(b)). Endlessly, the fluorescent focus contracted to raise the whole of glucose usage from 10 to $1500 \mu \mathrm{M}$, indicating that the extra $\mathrm{H}_{2} \mathrm{O}_{2}$ had been acquired with the glucose fixation conveyed (Figure $7(\mathrm{c})$ ). There is a remarkable synchronization association between glucose status and reduced fluorescence (Figure 7(d)).

Glucose plays a crucial role in living systems; so, blood glucose levels are an essential indicator of human and animal health conditions. To verify the feasibility of our approach to detect glucose in biological samples, it was applied to analyze glucose in fetal bovine serum samples. The glucose solutions with different concentrations of $0.1,0.8,1.5,3.0$, and $5.0 \mathrm{mM}$ were added into the $\mathrm{MoS}_{2}$ QDs/GOx/fetal bovine serum 


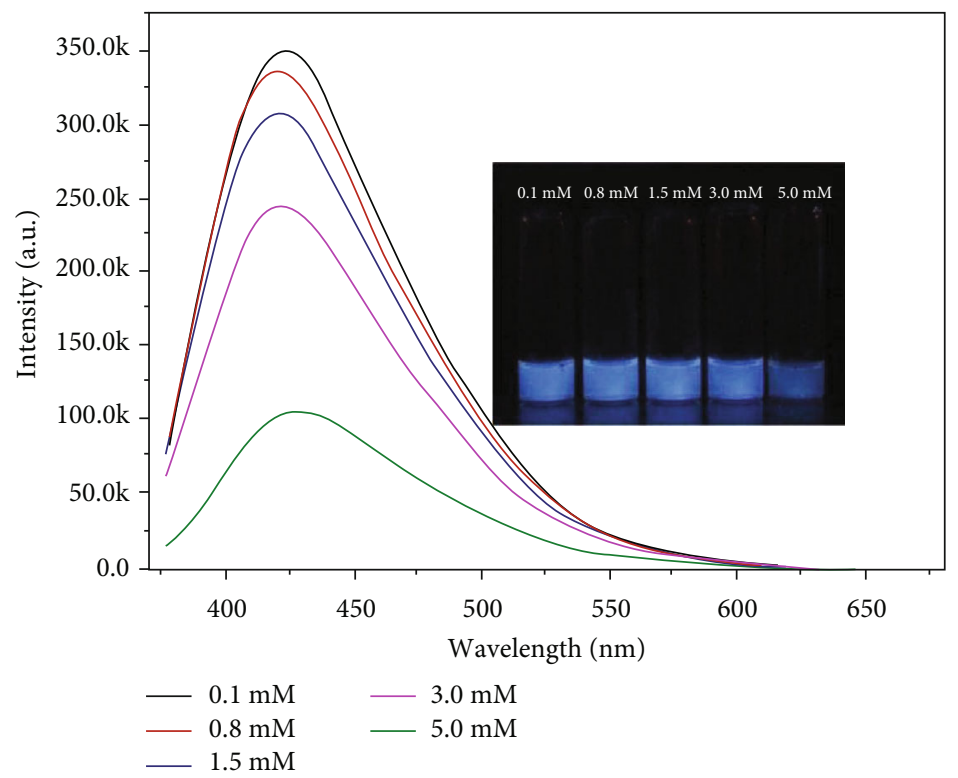

Figure 8: PL spectra of MoS2 QDs involving $0.2 \mathrm{mg} / \mathrm{mL}$ GOx with specific glucose fixations $(0.1,0.8,1.5,3.0$, and $5.0 \mathrm{mM})$ in fetal ox-like serum tests and pictures of $\mathrm{MoS}_{2}$ QDs with differentiating glucose focuses $(0.1,0.8,1.5,3.0$ and $5.0 \mathrm{mM})$ underneath $365 \mathrm{~nm}$ UV light (inset) [50].

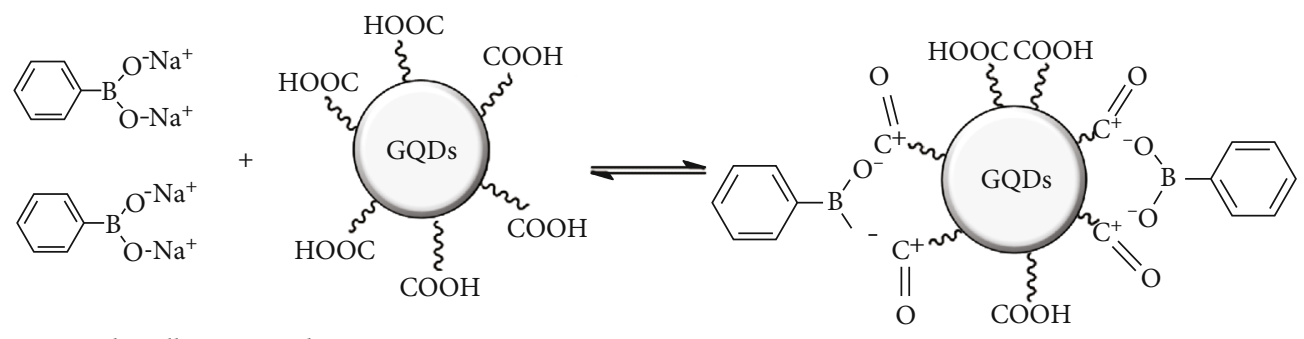

Phenylboronic acid sodium salt (PBS)

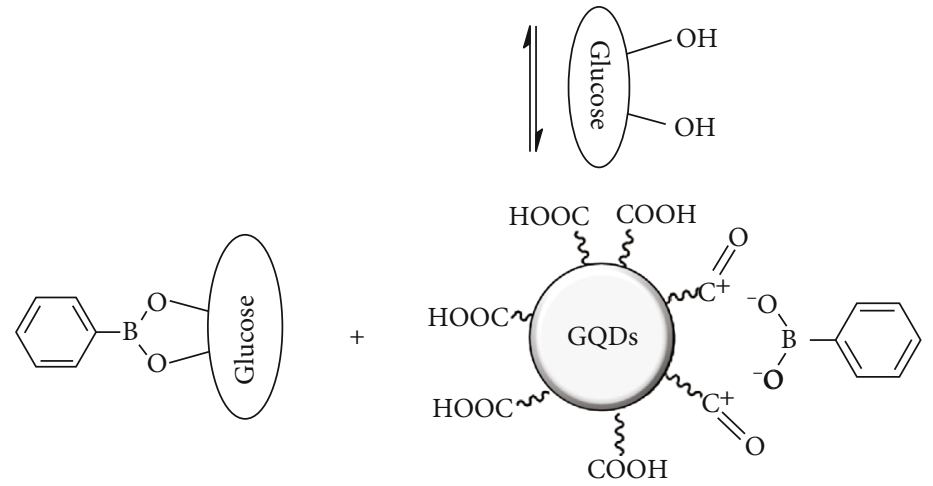

FIGURE 9: Chart scheme of the anticipated improvement and quenching component of GQD fluorescence [33].

TABLE 1: Detection of glucose in real blood serum samples [33].

\begin{tabular}{lccc}
\hline Samples & $\begin{array}{c}\text { Clinical data provided } \\
(\mathrm{mM})\end{array}$ & $\begin{array}{c}\text { Found } \\
(\mathrm{mM})\end{array}$ & $\begin{array}{c}\text { Recovery } \\
(\%)\end{array}$ \\
\hline S1 & 4.7 & 4.4 & 93.6 \\
S2 & 5.4 & 5.1 & 94.4 \\
S3 & 6.1 & 6.0 & 98 \\
S4 & 9.5 & 9.3 & 97.8 \\
\hline
\end{tabular}

mixture. Then, their fluorescence spectra were investigated. The results showed that the fluorescent intensity decreased gradually with increasing the concentration of glucose (Figure 8). It also can be found from photographs of the MoS2 QDs under $365 \mathrm{~nm}$ irradiation (inset of Figure 8) with different concentrations of glucose $(0.1,0.8,1.5,3.0$, and $5.0 \mathrm{mM})$. The results revealed that the proposed method is viable for practical blood glucose monitoring in the real sample [48]). 


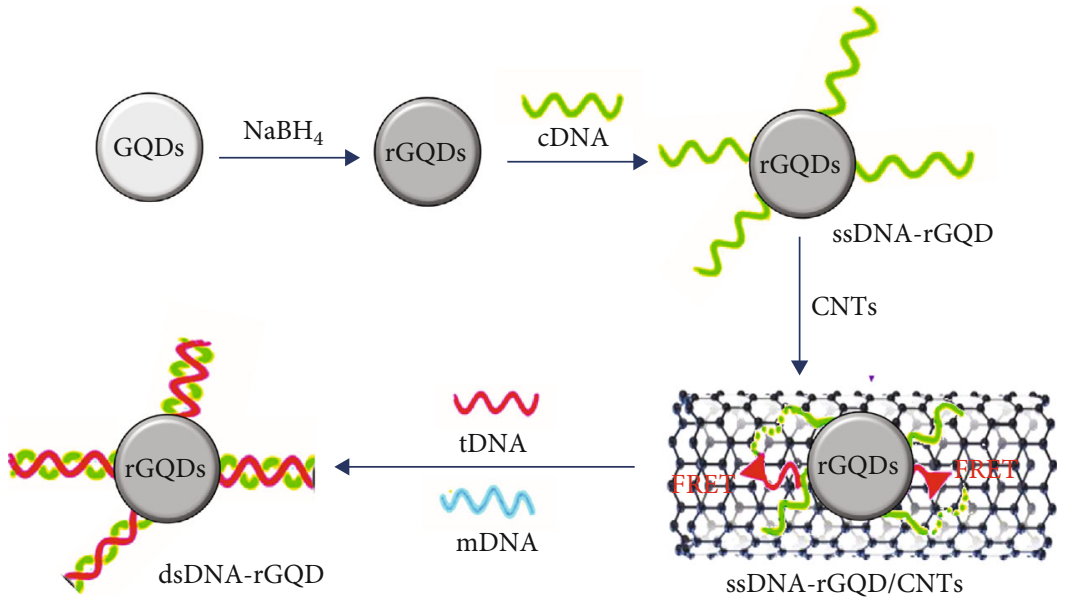

FIGURE 10: DNA discovery strategy of GQD-based fluorescence trade (FRET) nanosensor [57].

TABLE 2: Metal particle discovery utilizing fluorescence-based GQD sensors for biomedical applications [57].

\begin{tabular}{|c|c|c|c|c|}
\hline Nanomaterials & Target metal ion & Linear range & LOD & Reference \\
\hline GQDs & $\mathrm{Cu}^{2+}$ & $0-15 \mu \mathrm{M}$ & $0.226 \mu \mathrm{M}$ & [59] \\
\hline $\mathrm{r}-\mathrm{GQDs} / \mathrm{GO}$ & $\mathrm{Pb}^{2+}$ & $1-400 \mathrm{nM}$ & $0.6 \mathrm{nM}$ & {$[60]$} \\
\hline GQDs@AuNPs & $\mathrm{Pb}^{2+}$ & $50 \mathrm{nM}-4 \mu \mathrm{M}$ & $16.7 \mathrm{nM}$ & {$[61]$} \\
\hline N, S-GQDs & $\mathrm{Hg}^{2+}$ & $0.1-15 \mu \mathrm{M}$ & $0.14 \mathrm{nM}$ & {$[62]$} \\
\hline Val-GQDs & $\mathrm{Hg}^{2+}$ & $0.8 \mathrm{nM}-1 \mu \mathrm{M}$ & $0.4 \mathrm{nM}$ & {$[63]$} \\
\hline S-GQDs & $\mathrm{Ag}^{+}$ & $0.1-130 \mu \mathrm{M}$ & $30 \mathrm{nM}$ & {$[64]$} \\
\hline GQDs@OPD & $\mathrm{Ag}^{+}$ & $0-115.2 \mu \mathrm{M}$ & $250 \mathrm{nM}$ & {$[65]$} \\
\hline GQDs@AgNPs & $\mathrm{Ag}^{+}$ & $0-100 \mathrm{nM}$ & $3.5 \mathrm{nM}$ & {$[51]$} \\
\hline Cit-UCNPs/GQDs & $\mathrm{Ag}^{+}$ & $2 \times 10^{-4}-1 \mu \mathrm{M}$ & $60 \mathrm{pM}$ & {$[66]$} \\
\hline N-GQDs & $\mathrm{Fe}^{3+}$ & $1-1945 \mu \mathrm{M}$ & $90 \mathrm{nM}$ & [67] \\
\hline RBD-GQDs & $\mathrm{Fe}^{3+}$ & $0-1 \mu \mathrm{M}$ & $0.02 \mathrm{nM}$ & [68] \\
\hline N-GQDs & $\mathrm{Fe}^{3+}$ & $1-500 \mu \mathrm{M}$ & $1 \mu \mathrm{M}$ & [69] \\
\hline B-GQDs & $\mathrm{Fe}^{3+}$ & $50 \mathrm{nM}-420 \mu \mathrm{M}$ & $31.2 \mathrm{nM}$ & [70] \\
\hline DA-GQDs & $\mathrm{Fe}^{3+}$ & $20 \mathrm{nM}-2 \mu \mathrm{M}$ & $7.6 \mathrm{nM}$ & [71] \\
\hline S-GQDs & $\mathrm{Fe}^{3+}$ & $0.01-0.70 \mu \mathrm{M}$ & $4.2 \mathrm{nM}$ & {$[72]$} \\
\hline
\end{tabular}

Abbreviations: $\mathrm{Ag}^{+}$: silver ion; B-GQDs: boron-doped GQDs; Cit-UCNPs: sodium citrate functionalized up conversion nanoparticles; $\mathrm{Cu}^{2+}:$ copper (II) ion; DA-GQDs: dopamine-functionalized GQDs; $\mathrm{Fe}^{3+}$ : ferric (III) ion; GO: graphene oxide; GQDs: graphene quantum dots; $\mathrm{Hg}^{2+}$ : mercury (II) ion; N-GQDs: nitrogen-doped GQDs; N, S-GQDs: nitrogen and sulfur-doped GQDs; OPD: o-phenylene diamine; $\mathrm{Pb}^{2+}$ : lead (II) ion; RBD-GQDs: rhodaminefunctionalized GQDs; r-GQDs: reduced GQDs; N-GQDs: nitrogen-doped GQDs; $\mathrm{Pb}^{2+}$ : lead (II) ion; Val-GQDs: valine-functionalized GQDs.

To accept PBS-GQDs as glucose detection agents for diabetes diagnosis, sensing interference from other substances in human serum was studied. And after that, the PBS-GQD glucose sensor was tested on human serum (Figure 9). It was indicated that PBS-GQDs could detect and recognize glucose amongst four other saccharides such as galactose, fructose, sucrose, and lactose [33, 51-55].

\section{Glucose Detection in Real Blood Samples}

(Figure 5) reveals the quite different fluorescence effects of disaccharides on PBS-GQDs from other monosaccharides. Sucrose and lactose managed to improve the fluorescence effect of PBS-GQDs rather than to reduce it. It is noticeable that the affinity constants $(\mathrm{Ka})$ for binding of the fructose and galactose to the PBS-GQDs are greater than glucose. This suggests that the binding affinity strength is not the definitive parameter in the selective fluorescent detection of glucose. For example, fructose has no additional cis conformational diol unit to further bind with PBS-GQDs to form SQScontained aggregation though it is easier to combine with PBS-GQDs than glucose [35] covalently. (Table 1) shows the centralizations of glucose gathered, and the accommodating testing office gives the clinical focal points; recoveries reached out from $93.6 \%$ to $98 \%$.

\section{Fluorescence Resonance Energy Transfer- (FRET-) Based GQD Sensors}

As a general rule, weight can be a figure that trades without radiation necessities starting with one fluorophore then onto 


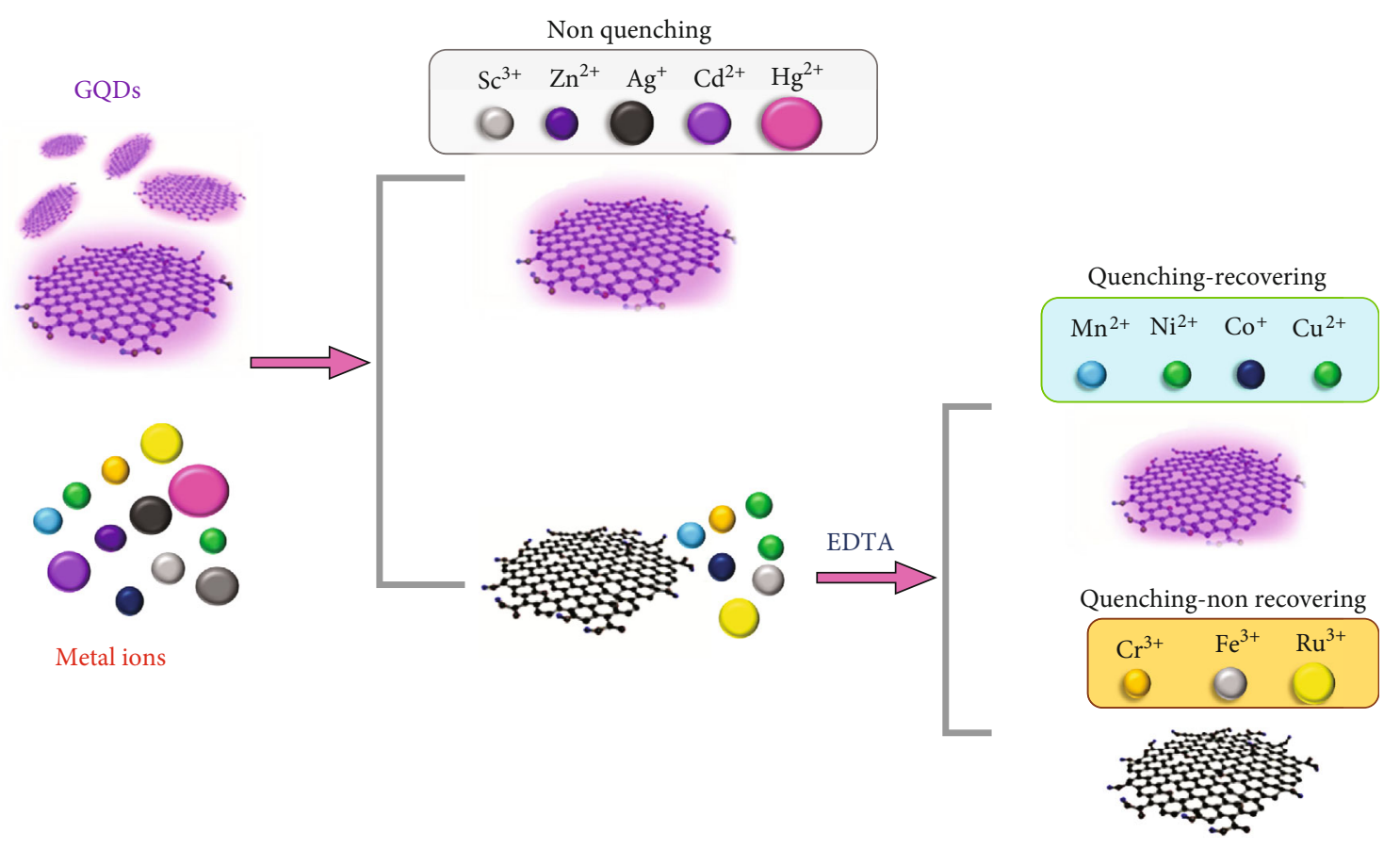

FIGURE 11: Diagram illustration of various transition metal ions and their possessions on the PL of GQDs [75].

the next, for example, from a supporter to an acceptor. In an all the more out and out headway, the vitality of the excitation light source is held by the maker. It is not radioactively traded to the acceptor, which is perhaps because of a spike in fluorescence. This subordinate separation feature is used to examine accomplice mixes inside the focal point of bioacknowledgment opportunities [56]. In development to recording, nearby single-cell fixation, worry subordinate sensors were joined to the cell-element board in heterogeneous cell peoples. In any case, in imparting scorn for their specific biomedical uses, these sensors are met with numerous difficulties. There is too an overwhelming requirement for extended affectability close by the advanced fluorescence sureness of Stress biosensors [56, 57].

As delineated in (Figure 10), Qianand partners told an object-based ultra-touchy DNA nanosensor among biogood GQDs and CNTs for target DNA quantitative examination $[7,57,58]$. Right now, progress has been completed by considering: (a) the base-coupling conduct of DNA, (b) specific worry among CNTs and DNA, and (c) vivacious fluorescence and outstanding biocompatibility of GQDs. CNTs and GQDs of QY up to 0.21 have by and by been self-luringly organizes as an equipped extinguishing expert and DNA fluorophore. Cry between oxidized CNTs and GQD evaluation was cultivated by the sensibility of their self-getting together by the stacking of $\pi-l$. Agreeing to Whine from GQDs and CNTs, regular “on-off” fluorescence was begun from fluorescence extinguishing $(30 \mathrm{~min})$ reasonable as the resulting fluorescence recovery $(30 \mathrm{~min})$ was because of free twofold stranded (ds) DNA released.

As of late, GQD-sensor subordinate to fluorescence has been showing up to assess the grouped assortment of metal particles, for illustration, $\mathrm{Ag}^{+}, \mathrm{Pb}^{2+}, \mathrm{Cu}^{2}, \mathrm{Hg}^{2+}$, and $\mathrm{Fe}^{3+}$ par- ticles. These sensors may be sensible for characteristic security to recognize metal particles in water tests to expand clinical affirmation of a few dangerous developments. Sorts for the case, taking after the $\mathrm{Fe}^{3+}$ molecule organizes in human serum can offer assistance in danger finding. Interior of the improvement of such sensors, either GQD itself or its functionalized assortments with $\mathrm{GO}$, nitrogen, rhodamine, dopamine, sulfur, boron, amino acids like valine, or for beyond any doubt when gotten at the side nanomaterials, e.g., gold nanoparticles (AuNPs), silver nanoparticles (AgNPs), and sodium citrate-functionalized nanoparticles (Cit-UCNPs), have accomplished interior the bolstered highlights of the person biosensors (Table 2).

The closeness of harming boronic packs on the B-surface can pass on PL for title glucose positioning [12, 58]. Before that, this incites the intramolecular switch, pushing up to a raised PL. Likewise, it has been outlined that B-GQDs can be phenomenally sporadic as glucose instead of isomeric family people, for representation, fructose, mannose, and galactose inferable from their ability to instigate missing from saccharides with as much as one cis-diol band. A short timeframe subsequently tendencies the intramolecular development, inciting an energized PL change. Truly, it has been delineated that B-GQDs can well be essentially remarkable to glucose as confined to its isomeric family people, for the case, fructose, mannose, and galactic [73]. Here, among GQDs and $\mathrm{Fe}^{3+5}, 10,15,20$-tetrakis (1-methyl-4-pyridyl) porphin (FeTMPyP) was wrapped up the production of multifunctional and noncovalent mutts. The GQD's PL was stifled on the GQDs by FeTMPyP's inside channel influence (IFE). By then, the stifled PL of GQDs can be traded "up" according to the fitting response that occurred amidst FeTMPyP and $\mathrm{H}_{2} \mathrm{O}_{2}$ that caused the cyclic tetrapyrrolic focus to 
break. $\mathrm{Fe}^{3+}$ particles from FeTMPyP are lost right directly, dreary mono- and dipyrrole. This "turn-on" estimation framework will give an unquestionable game plan plot to centralizations of glucose and $\mathrm{H}_{2} \mathrm{O}_{2}$ from 3 to $100 \mu \mathrm{M}$ and 2 to $300 \mu \mathrm{M}$, freely, with an intricacy some spot inside the reach out of 0.5 and $0.3 \mu \mathrm{M}$ LOD values. Shehab et al. masterminded the usage of phenylboronic harming receptor-GQDs for a nonglucose sensor, where the PL of GQDs was viewed as the key optical parameter for glucose [33]. This sensor may seem a great organized relationship for glucose upkeep fluctuating from 4 to 40 $\mathrm{mM}$ ( 72 to $720 \mathrm{mg} \mathrm{dL}-1)$, with a $3.0 \mathrm{mM}$ LOD. As appeared in (Figure 11), Huang and the bundle proposed another PLset-up electron move approach depending on the dousing of assorted moving metal particles on GQD focused PL [74].

\section{Conclusion}

Diabetes could be a metabolic issue, delineated by blood glucose fixations, and causes general take mischief and bafflement of various organs, such as kidney, heart, eyes, and veins. The first and kind affirmation of unusual glucose levels inside the blood is vital for reasonable treatment to diminish different helpful issues. Currently, the accessible glucometers available offer just intrusive, nonconstant measures. Noninvasive, real-time, and advantageous sensors for glucose detection need to be created. An alternate approach may be to merge nanotechnology with fluorescence technologies. Starting late, fluorescent GQDs, one sort of zerodimensional graphene sheets with sidelong measure under $100 \mathrm{~nm}$, have pulled in examiners since their strong run of the mill and substance dormancy, moo cytotoxicity, and excellent biocompatibility, and insurance. Because of their earth-shattering properties, GQDs are the potential opportunities for bioimaging, invention, and regular recognizing, photocatalysis, and electrocatalysis. The various courses of action frameworks of GQDs were portrayed. In this way, a couple of approaches have been fixated on the social affair, and the glucose biosensors subordinate to glucose oxidase proteins and nitrogen-doped fluorescent GQDs. Biocompatibility and properties of fluorescent nitrogen-doped graphene quantum dots for controlling diabetes have been improved with many years of exertion. For instance, the high quantum yield and photostability of semiconductor quantum dots make them alluring to look into and develop. With the advent of advanced production processes, including three-dimensional (3D) printing and nano/microscale assembly, in noninvasive and/or embedded applications, nanostructured biosensors may be used to provide more efficient data collection models for constant, user-friendly, and real-time glucose control interventions for diabetes. For glucose sensing in the food and pharmaceutical sectors, for the long-term usage of nanostructured glucose biosensors, reliability and longevity in extreme environments such as heat/cold, saline, and acid/primary conditions need to be taken into account.

\section{Data Availability}

All data used to support the findings of this study are included within the article.

\section{Conflicts of Interest}

The authors declare they have no competing interests.

\section{Acknowledgments}

The authors wish to thank Dr. Nasrin Shokrpour at the Research Consultation Center (RCC) of Shiraz University of Medical Sciences for his invaluable assistance in editing this manuscript. This work was supported by the vicechancellor of research, Shiraz University of Medical Sciences.

\section{References}

[1] F. Emadi, A. Amini, A. Gholami, and Y. Ghasemi, "Functionalized graphene oxide with chitosan for protein nanocarriers to protect against enzymatic cleavage and retain collagenase activity," Scientific Reports, vol. 7, no. 1, 2017.

[2] C. Chen, Q. Xie, D. Yang et al., "Recent advances in electrochemical glucose biosensors: a review," RSC Advances, vol. 3, no. 14, pp. 4473-4491, 2013.

[3] P. Zhang, X. Zhao, Y. Ji et al., "Electrospinning graphene quantum dots into a nanofibrous membrane for dual-purpose fluorescent and electrochemical biosensors," Journal of Materials Chemistry B, vol. 3, no. 12, pp. 2487-2496, 2015.

[4] A. Gholami, M. H. Dabbaghmanesh, Y. Ghasemi, P. Talezadeh, F. Koohpeyma, and N. Montazeri-Najafabady, "Probiotics ameliorate pioglitazone-associated bone loss in diabetic rats," Diabetology \& Metabolic Syndrome, vol. 12, no. $1,2020$.

[5] S. M. Mousavi, S. A. Hashemi, M. Zarei et al., "Recent progress in chemical composition, production, and pharmaceutical effects of kombucha beverage: a complementary and alternative medicine," Evidence-based Complementary and Alternative Medicine, vol. 2020, 14 pages, 2020.

[6] S. Jahandideh, M. J. Sarraf Shirazi, M. Tavakoli, S. M. Mousavi, and S. A. Hashemi, "High mechanical and thermal performance of Sasobit-modified epoxy resin, prepared via vacuum shock technique," Polymer Testing, vol. 81, p. 106171, 2020.

[7] S. Mazraedoost and G. Behbudi, "Basic nano magnetic particles and essential oils: biological applications," Journal of Environmental Treatment Techniques, vol. 9, no. 3, pp. 609-620, 2021.

[8] R. Masoumzade, G. Behbudi, and S. Mazraedoost, "A medical encyclopedia with new approach graphene quantum dots for anti-breast cancer applications: mini review," Advances in Applied NanoBio-Technologies, vol. 1, no. 4, pp. 84-90, 2020.

[9] L. Chen, E. Hwang, and J. Zhang, "Fluorescent nanobiosensors for sensing glucose," Sensors, vol. 18, no. 5, p. 1440, 2018.

[10] S. A. Hashemi, S. M. Mousavi, S. Bahrani, S. Ramakrishna, A. Babapoor, and W. H. Chiang, "Coupled graphene oxide with hybrid metallic nanoparticles as potential electrochemical biosensors for precise detection of ascorbic acid within blood," Analytica Chimica Acta, vol. 1107, pp. 183-192, 2020.

[11] S. Mazraedoost and G. Behbudi, "Nano materials-based devices by photodynamic therapy for treating cancer applications," Advances in Applied NanoBio-Technologies, vol. 2, no. 3, pp. 9-21, 2021.

[12] R. Madhu, V. Veeramani, S. M. Chen, A. Manikandan, A. Y. Lo, and Y. L. Chueh, "Honeycomb-like porous carbon-cobalt oxide nanocomposite for high-performance enzymeless 
glucose sensor and supercapacitor applications," ACS Applied Materials \& Interfaces, vol. 7, no. 29, pp. 15812-15820, 2015.

[13] F. Emadi, A. Emadi, and A. Gholami, "A comprehensive insight towards pharmaceutical aspects of graphene nanosheets," Current Pharmaceutical Biotechnology, vol. 21, no. 11, pp. 1016-1027, 2020.

[14] K. Yousefi, N. Parvin, N. Banaei, and S. Mazraedoost, "Waterborne polyurethanes for high-performance electromagnetic interference shielding," Advances in Applied NanoBio-Technologies, vol. 2, no. 3, pp. 35-45, 2021.

[15] S. A. Hashemi, N. G. Golab Behbahan, S. Bahrani et al., "Ultrasensitive viral glycoprotein detection nanosystem toward accurate tracing SARS-CoV-2 in biological/non-biological media," Biosensors and Bioelectronics, vol. 171, p. 112731, 2021.

[16] A. Gholami, S. A. Hashemi, K. Yousefi et al., "3D nanostructures for tissue engineering, cancer therapy, and gene delivery," Journal of Nanomaterials, vol. 2020, 24 pages, 2020.

[17] S. M. Mousavi, S. A. Hashemi, M. Arjmand, A. M. Amani, F. Sharif, and S. Jahandideh, "Octadecyl amine functionalized graphene oxide towards hydrophobic chemical resistant epoxy nanocomposites," ChemistrySelect, vol. 3, no. 25, pp. $7200-$ 7207, 2018.

[18] K. E. Toghill, L. Xiao, M. A. Phillips, and R. G. Compton, “The non-enzymatic determination of glucose using an electrolytically fabricated nickel microparticle modified boron-doped diamond electrode or nickel foil electrode," Sensors and Actuators B: Chemical, vol. 147, no. 2, pp. 642-652, 2010.

[19] S. M. Mousavi, S. A. Hashemi, N. Parvin et al., "Carbon substrates for flexible supercapacitors and energy storage applications," Flexible Supercapacitor Nanoarchitectonics, pp. 95-141, 2021, https://onlinelibrary.wiley.com/doi/10.1002/ 9781119711469.ch5.

[20] S. A. Hashemi, S. M. Mousavi, R. Faghihi, M. Arjmand, S. Sina, and A. M. Amani, "Lead oxide-decorated graphene oxide/epoxy composite towards X-ray radiation shielding," Radiation Physics and Chemistry, vol. 146, pp. 77-85, 2018.

[21] S. Samuei, J. Fakkar, Z. Rezvani, A. Shomali, and B. Habibi, "Synthesis and characterization of graphene quantum dots/CoNiAl-layered double- hydroxide nanocomposite: application as a glucose sensor," Analytical Biochemistry, vol. 521, pp. 31-39, 2017.

[22] S. Mazraedoost and N. Banaei, "Biochemical composition properties of kombucha SCOBY: mini reviews," Advances in Applied NanoBio-Technologies, vol. 1, no. 4, pp. 99-104, 2020.

[23] N. Goudarzian, S. Samiei, F. Safari, S. M. Mousavi, S. A. Hashemi, and S. Mazraedoost, "Enhancing the physical, mechanical, oxygen permeability and photodegradation properties of styrene-acrylonitrile (SAN), butadiene rubber (BR) composite by silica nanoparticles," Journal of Environmental Treatment Techniques, vol. 8, no. 2, pp. 718-726, 2020.

[24] J. E. T. Tech, "Investigating the activity of antioxidants activities content in Apiaceae and to study antimicrobial and insecticidal activity of antioxidant by using SPME Fiber assembly carboxen/polydimethylsiloxane (CAR/PDMS)," Journal of Environmental Treatment Techniques, vol. 8, no. 1, pp. 214224, 2020.

[25] S. M. Mousavi, S. A. Hashemi, M. Zarei, A. M. Amani, and A. Babapoor, "Nanosensors for chemical and biological and medical applications," Medicinal Chemistry, vol. 8, no. 8, 2018.

[26] S. M. Mousavi, S. A. Hashemi, Y. Ghasemi, A. M. Amani, A. Babapoor, and O. Arjmand, "Applications of graphene oxide in case of nanomedicines and nanocarriers for biomolecules: review study," Drug Metabolism Reviews, vol. 51, no. 1, pp. 12-41, 2019.

[27] A. Zakeri, M. A. J. Kouhbanani, N. Beheshtkhoo et al., "Polyethylenimine-based nanocarriers in co-delivery of drug and gene: a developing horizon," Nano Reviews \& Experiments, vol. 9, no. 1, p. 1488497, 2018.

[28] Y. Dong, J. Shao, C. Chen et al., "Blue luminescent graphene quantum dots and graphene oxide prepared by tuning the carbonization degree of citric acid," Carbon, vol. 50, no. 12, pp. 4738-4743, 2012.

[29] R. Liu, D. Wu, X. Feng, and K. Müllen, "Bottom-up fabrication of photoluminescent graphene quantum dots with uniform morphology," Journal of the American Chemical Society, vol. 133, no. 39, pp. 15221-15223, 2011.

[30] P. N. Joshi, S. Kundu, S. K. Sanghi, and D. Sarkar, "Graphene quantum dots-from emergence to nanotheranostic applications, in smart drug delivery system," in Smart Drug Delivery System, pp. 159-195, INTECH, 2016.

[31] X. Wu, F. Tian, W. Wang, J. Chen, M. Wu, and J. X. Zhao, "Fabrication of highly fluorescent graphene quantum dots using L-glutamic acid for in vitro/in vivo imaging and sensing," Journal of Materials Chemistry C, vol. 1, no. 31, pp. 4676-4684, 2013.

[32] L. Wang and H. S. Zhou, "Green synthesis of luminescent nitrogen-doped carbon dots from milk and its imaging application," Analytical Chemistry, vol. 86, no. 18, pp. 8902-8905, 2014.

[33] M. Shehab, S. Ebrahim, and M. Soliman, "Graphene quantum dots prepared from glucose as optical sensor for glucose," Journal of Luminescence, vol. 184, pp. 110-116, 2017.

[34] L. Ponomarenko, F. Schedin, M. I. Katsnelson et al., "Chaotic dirac billiard in graphene quantum dots," Science, vol. 320, no. 5874, pp. 356-358, 2008.

[35] J. Peng, W. Gao, B. K. Gupta et al., "Graphene quantum dots derived from carbon fibers," Nano Letters, vol. 12, no. 2, pp. 844-849, 2012.

[36] A. Gholami, F. Emadi, A. Amini, M. Shokripour, M. Chashmpoosh, and N. Omidifar, "Functionalization of graphene oxide nanosheets can reduce their cytotoxicity to dental pulp stem cells," Journal of Nanomaterials, vol. 2020, 14 pages, 2020.

[37] Y. Li, Y. Hu, Y. Zhao et al., "An electrochemical avenue to green-luminescent graphene quantum dots as potential electron-acceptors for photovoltaics," Advanced Materials, vol. 23, no. 6, pp. 776-780, 2011.

[38] L. Bao, Z. L. Zhang, Z. Q. Tian et al., "Electrochemical tuning of luminescent carbon nanodots: from preparation to luminescence mechanism," Advanced Materials, vol. 23, no. 48, pp. 5801-5806, 2011.

[39] S. Zhu, Y. Song, J. Wang et al., "Photoluminescence mechanism in graphene quantum dots: quantum confinement effect and surface/edge state," Nano Today, vol. 13, pp. 10-14, 2017.

[40] M. Mitchell, "New nanoparticles bring cheaper, lighter solar cells outdoors8-242014, Rdmag.com.

[41] Y. Xuan, R. Y. Zhang, X. S. Zhang et al., “Targeting N-doped graphene quantum dot with high photothermal conversion efficiency for dual-mode imaging and therapy in vitro," Nanotechnology, vol. 29, no. 35, p. 355101, 2018.

[42] Y. Du and S. Guo, "Chemically doped fluorescent carbon and graphene quantum dots for bioimaging, sensor, catalytic and 
photoelectronic applications," Nanoscale, vol. 8, no. 5, pp. 2532-2543, 2016.

[43] C.-B. Ma, Z. T. Zhu, H. X. Wang et al., "A general solid-state synthesis of chemically-doped fluorescent graphene quantum dots for bioimaging and optoelectronic applications," Nanoscale, vol. 7, no. 22, pp. 10162-10169, 2015.

[44] Y. F. Kang, Y. H. Li, Y. W. Fang, Y. Xu, X. M. Wei, and X. B. Yin, "Carbon quantum dots for zebrafish fluorescence imaging," Scientific Reports, vol. 5, no. 1, pp. 1-12, 2015.

[45] X. Gong, W. Lu, M. C. Paau et al., "Facile synthesis of nitrogendoped carbon dots for $\mathrm{Fe}^{3+}$ sensing and cellular imaging," Analytica Chimica Acta, vol. 861, pp. 74-84, 2015.

[46] A. Ananthanarayanan, Y. Wang, P. Routh et al., "Nitrogen and phosphorus co-doped graphene quantum dots: synthesis from adenosine triphosphate, optical properties, and cellular imaging," Nanoscale, vol. 7, no. 17, pp. 8159-8165, 2015.

[47] L. Lin, X. Song, Y. Chen et al., "Intrinsic peroxidase-like catalytic activity of nitrogen-doped graphene quantum dots and their application in the colorimetric detection of $\mathrm{H}_{2} \mathrm{O}_{2}$ and glucose," Analytica Chimica Acta, vol. 869, pp. 89-95, 2015.

[48] W. Guan, W. Zhou, J. Lu, and C. Lu, "Luminescent films for chemo- and biosensing," Chemical Society Reviews, vol. 44, no. 19, pp. 6981-7009, 2015.

[49] P. D. Howes, R. Chandrawati, and M. M. Stevens, "Colloidal nanoparticles as advanced biological sensors," Science, vol. 346, no. 6205, 2014.

[50] X. Wang, Q. Wu, K. Jiang, C. Wang, and C. Zhang, "One-step synthesis of water-soluble and highly fluorescent $\mathrm{MoS}_{2}$ quantum dots for detection of hydrogen peroxide and glucose," Sensors and Actuators B: Chemical, vol. 252, pp. 183-190, 2017.

[51] X. Ran, H. Sun, F. Pu, J. Ren, and X. Qu, "Ag nanoparticledecorated graphene quantum dots for label-free, rapid and sensitive detection of Ag+ and biothiols," Chemical Communications, vol. 49, no. 11, pp. 1079-1081, 2013.

[52] S. Zhu, J. Zhang, S. Tang et al., "Surface chemistry routes to modulate the photoluminescence of graphene quantum dots: from fluorescence mechanism to up-conversion bioimaging applications," Advanced Functional Materials, vol. 22, no. 22, pp. 4732-4740, 2012.

[53] M. Mirzababaei, K. Larijani, H. Hashemi-Moghaddam, Z. Mirjafary, and H. Madanchi, "In vitro targeting of NL2 peptide bounded on poly L-DOPA coated graphene quantum dot," Journal of Fluorescence, vol. 31, no. 1, pp. 279-288, 2021.

[54] G. Lui, J. Y. Liao, A. Duan, Z. Zhang, M. Fowler, and A. Yu, "Graphene-wrapped hierarchical TiO 2 nanoflower composites with enhanced photocatalytic performance," Journal of Materials Chemistry A, vol. 1, no. 39, pp. 12255-12262, 2013.

[55] W. Wu, T. Zhou, A. Berliner, P. Banerjee, and S. Zhou, "Glucose-mediated assembly of phenylboronic acid modified $\mathrm{CdTe} / \mathrm{ZnTe} / \mathrm{ZnS}$ quantum dots for intracellular glucose probing," Angewandte Chemie International Edition, vol. 49, no. 37, pp. 6554-6558, 2010.

[56] S. Zadran, S. Standley, K. Wong, E. Otiniano, A. Amighi, and M. Baudry, "Fluorescence resonance energy transfer (FRET)based biosensors: visualizing cellular dynamics and bioenergetics," Applied Microbiology and Biotechnology, vol. 96, no. 4, pp. 895-902, 2012.

[57] Z. S. Qian, X. Y. Shan, L. J. Chai, J. J. Ma, J. R. Chen, and H. Feng, "DNA nanosensor based on biocompatible graphene quantum dots and carbon nanotubes," Biosensors and Bioelectronics, vol. 60, pp. 64-70, 2014.
[58] Z. S. Qian, X. Y. Shan, L. J. Chai, J. J. Ma, J. R. Chen, and H. Feng, "A universal fluorescence sensing strategy based on biocompatible graphene quantum dots and graphene oxide for the detection of DNA," Nanoscale, vol. 6, no. 11, pp. 5671-5674, 2014.

[59] F. Wang, Z. Gu, W. Lei, W. Wang, X. Xia, and Q. Hao, "Graphene quantum dots as a fluorescent sensing platform for highly efficient detection of copper(II) ions," Sensors and Actuators B: Chemical, vol. 190, pp. 516-522, 2014.

[60] Z. S. Qian, X. Y. Shan, L. J. Chai, J. R. Chen, and H. Feng, "A fluorescent nanosensor based on graphene quantum dotsaptamer probe and graphene oxide platform for detection of lead (II) ion," Biosensors and Bioelectronics, vol. 68, pp. 225-231, 2015.

[61] X. Niu, Y. Zhong, R. Chen, F. Wang, Y. Liu, and D. Luo, "A "turn-on" fluorescence sensor for $\mathrm{Pb}^{2+}$ detection based on graphene quantum dots and gold nanoparticles," Sensors and Actuators B: Chemical, vol. 255, pp. 1577-1581, 2018.

[62] N. T. N. Anh, A. D. Chowdhury, and R.-a. Doong, "Highly sensitive and selective detection of mercury ions using N, Scodoped graphene quantum dots and its paper strip based sensing application in wastewater," Sensors and Actuators B: Chemical, vol. 252, pp. 1169-1178, 2017.

[63] Z. Xiaoyan, L. Zhangyi, and L. Zaijun, "Fabrication of valinefunctionalized graphene quantum dots and its use as a novel optical probe for sensitive and selective detection of $\mathrm{Hg}^{2}+$," Spectrochimica Acta Part A: Molecular and Biomolecular Spectroscopy, vol. 171, pp. 415-424, 2017.

[64] S. Bian, C. Shen, Y. Qian, J. Liu, F. Xi, and X. Dong, "Facile synthesis of sulfur-doped graphene quantum dots as fluorescent sensing probes for $\mathrm{Ag}^{+}$ions detection," Sensors and Actuators B: Chemical, vol. 242, pp. 231-237, 2017.

[65] X.-E. Zhao, C. Lei, Y. Gao et al., "A ratiometric fluorescent nanosensor for the detection of silver ions using graphene quantum dots," Sensors and Actuators B: Chemical, vol. 253, pp. 239-246, 2017.

[66] L. He, L. Yang, H. Zhu, W. Dong, Y. Ding, and J. J. Zhu, “A highly sensitive biosensing platform based on upconversion nanoparticles and graphene quantum dots for the detection of Ag+," Methods and applications in fluorescence, vol. 5, no. 2, article 024010, 2017.

[67] J. Ju and W. Chen, "Synthesis of highly fluorescent nitrogendoped graphene quantum dots for sensitive, label-free detection of Fe (III) in aqueous media," Biosensors and Bioelectronics, vol. 58, pp. 219-225, 2014.

[68] R. Guo, S. Zhou, Y. Li, X. Li, L. Fan, and N. H. Voelcker, "Rhodamine-functionalized graphene quantum dots for detection of $\mathrm{Fe} 3+$ in cancer stem cells," ACS Applied Materials \& Interfaces, vol. 7, no. 43, pp. 23958-23966, 2015.

[69] T. Van Tam, N. B. Trung, H. R. Kim, J. S. Chung, and W. M. Choi, "One-pot synthesis of N-doped graphene quantum dots as a fluorescent sensing platform for $\mathrm{Fe}^{3+}$ ions detection," Sensors and Actuators B: Chemical, vol. 202, pp. 568-573, 2014.

[70] S. Ge, J. He, C. Ma, J. Liu, F. Xi, and X. Dong, “One-step synthesis of boron-doped graphene quantum dots for fluorescent sensors and biosensor," Talanta, vol. 199, pp. 581-589, 2019.

[71] A. Dutta Chowdhury and R. A. Doong, "highly sensitive and selective detection of nanomolar ferric ions using dopamine functionalized graphene quantum dots," ACS Applied Materials \& Interfaces, vol. 8, no. 32, pp. 21002-21010, 2016.

[72] S. Li, Y. Li, J. Cao, J. Zhu, L. Fan, and X. Li, "Sulfur-doped graphene quantum dots as a novel fluorescent probe for highly 
selective and sensitive detection of Fe3+," Analytical Chemistry, vol. 86, no. 20, pp. 10201-10207, 2014.

[73] L. Zhang, D. Peng, R. P. Liang, and J. D. Qiu, "Graphene quantum dots assembled with metalloporphyrins for "Turn on" sensing of hydrogen peroxide and glucose," Chemistry-A European Journal, vol. 21, no. 26, pp. 9343-9348, 2015.

[74] Y. Li, Y. Jiang, T. Mo, H. Zhou, Y. Li, and S. Li, "Highly selective dopamine sensor based on graphene quantum dots selfassembled monolayers modified electrode," Journal of Electroanalytical Chemistry, vol. 767, pp. 84-90, 2016.

[75] H. Huang, L. Liao, X. Xu, M. Zou, F. Liu, and N. Li, “The electron-transfer based interaction between transition metal ions and photoluminescent graphene quantum dots (GQDs): a platform for metal ion sensing," Talanta, vol. 117, pp. 152157, 2013. 